\title{
Abordagem clínica na análise da atividade docente: uma via unindo pesquisa, intervenção e formação ${ }^{1}$
}

\author{
Rozania Maria Alves de Moraes* \\ Elisandra Maria Magalhães ${ }^{* *}$
}

\begin{abstract}
Resumo
A conjugação entre pesquisa e intervenção na Clínica da Atividade é um assunto que, aparentemente, ainda não se esgotou, suscitando importantes discussões entre especialistas da área. Este artigo tem como objetivo discutir experiências trazidas de duas pesquisas de caráter interventivo realizadas na formação inicial de professores de língua francesa, utilizando as abordagens clínica e ergonômica da atividade; além disso, busca também mostrar que, nas situações apresentadas, pesquisa e intervenção se mostram inseparáveis, e que, em ambas as pesquisas, é perceptível a ampliação do poder de agir dos sujeitos - objetivo da Clínica da Atividade. Esses resultados apontam para uma nova via que se abre para a formação inicial de professores de línguas.
\end{abstract}

Palavras-chave: Abordagem Clínica; Atividade Docente; Pesquisa; Intervenção; Formação.

\section{Clinical approach in the analysis of teaching activity: A path linking research, intervention and training}

\begin{abstract}
The combination of research and intervention in the Clinic of Activity is a subject that, apparently, has not yet been exhausted, provoking important discussions among specialists in the area. This article aims to discuss the experiences of two interventional studies carried out in the initial training of French teachers, using the clinical and ergonomic approaches of the activity. It also seeks to show that, in the situations presented, research and intervention are inseparable, and that in both researches, the increase in the power of action of the subjects - objective of the Clinic of Activity - is noticeable. These results point to a new path that opens to the initial training of language teachers.

Keywords: Clinical Approach; Teaching Activity; Search; Intervention; Training.
\end{abstract}

\section{Introdução}

A área de formação de professores de línguas no Brasil tem recebido nos últimos anos produtivas contribuições intermediadas pela Linguística Aplicada (doravante LA) e por seu diálogo com diferentes áreas de conhecimento, a saber: educação, psicologia, sociologia, fonoaudiologia, enfermagem e direito, para citar apenas algumas.

Consciente do caráter multi/pluri/interdisciplinar da LA, Celani (1998, p. 117) aborda ainda uma visão transdisciplinar para a LA numa "colaboração de disciplinas". Para a autora, isto não significa simplesmente uma justaposição de saberes, mas um envolvimento efetivo dos pesquisadores em suas respectivas áreas.

Estudos sobre formação de professores de línguas avançam abordando aspectos que vão além do processo de ensino e aprendizagem, dos materiais, dos métodos e abordagens e das avaliações, por exemplo; e contemplam também o ensino como trabalho, ou seja, a atividade laboral do professor, focalizando as relações entre

*Endereço eletrônico: r_de_moraes@hotmail.com

*** Endereço eletrônico: elisandrafortaleza@hotmail.com linguagem e trabalho. Situando-se nessa linha de estudos, surgem no Brasil, nos anos 1990-2000, os trabalhos desenvolvidos por grupos de estudos da Pontifícia Universidade Católica, de São Paulo, e da Universidade de São Paulo, tendo à frente Maria Cecília Souza-e-Silva e Anna Rachel Machado, respectivamente, professoras aliadas a pesquisadores franceses (Universidade de Provence, atualmente, Aix-Marseille) e suíços (Universidade de Genebra).

Interessou-nos, sobremaneira, aprofundar conhecimentos atinentes a essa abordagem adotada pelos referidos pesquisadores, tendo em vista que nossa experiência com a formação de professores de língua francesa, no curso de Letras da Universidade Estadual do Ceará (de agora em diante UECE) que carece justamente de uma proposta que traga "contribuições para o aprofundamento da compreensão do trabalho do professor e, consequentemente, da sua formação" (MACHADO, 2004, p. x).

Compartilhamos deste posicionamento de Machado (2004), que se completa com o pensamento de Freire (1996, p. 9) de que "formar é muito mais do que puramente treinar o educando 
no desempenho de destrezas", mas, é também torná-lo consciente do importante papel que (deve) exerce(r) "para a avaliação crítica do processo de construção da ação pedagógica e sua reconstrução", afirma Lima (2012, p. 37), também fundamentada em Freire naquela mesma obra.

Os estágios supervisionados em ensino de línguas estrangeiras do Curso de Letras da UECE, realizados, em sua maioria, através de um projeto de extensão deste curso - o Núcleo de Línguas Estrangeiras - permitem aos estagiários, futuros professores, a experiência de assumirem uma sala de aula, supervisionados por um coordenador pedagógico e por um professor formador. Nesta experiência já devem, portanto, e evidentemente, seguir tudo aquilo que demanda o métier, ainda que na condição de "professor iniciante". Partindo dessa premissa, surgem inúmeros questionamentos, tanto da parte do formador quanto da parte do formando. Para os iniciantes, as incertezas e inseguranças são ainda constantes na sua prática. Para o formador, a preocupação e o compromisso de levar o formando à aprendizagem e à realização de uma prática concreta e eficaz.

$\mathrm{O}$ contato com as abordagens clínica e ergonômica da atividade, por intermédio dos estudos de Machado (2004), Souza-e-Silva e Faïta (2002) e das trocas estabelecidas nos últimos anos com os pesquisadores da equipe ERGAPE (Ergonomia da Atividade dos Profissionais da Educação) da Universidade Aix-Marseille, faznos refletir sobre uma formação que conduza o futuro profissional a desenvolver um olhar clínico sobre sua própria atividade em direção à compreensão e à transformação desta atividade $\mathrm{e}$ de seu próprio desenvolvimento (como) profissional. Para isso, consideramos a possibilidade de utilizarmos conhecimentos (resultados) oriundos de pesquisas a fim de mobilizá-los como "meio de agir e de pensar" (CLOT, 2008) a serviço dos professores em formação.

O presente artigo tem como objetivo discutir experiências trazidas de duas pesquisas de caráter interventivo realizadas na formação inicial de professores de língua francesa, utilizando as abordagens clínica e ergonômica da atividade; além disso, busca também mostrar que, nas situações apresentadas, pesquisa e intervenção se mostram inseparáveis, e que, em ambas as pesquisas, é perceptível a ampliação do poder de agir dos sujeitos - objetivo da Clínica da Atividade.

Seguindo esse pensamento, apresentamos neste artigo alguns aspectos relativos à Clínica da Atividade numa tentativa de vislumbrar, na formação de professores, uma abordagem que busca não apenas "compreender para transformar", mas também "transformar para compreender". Para tanto, apresentamos, de modo não exaustivo, a Clínica da Atividade, seguida dos princípios teóricos e metodológicos, sobretudo aqueles empregados nas investigações que realizamos em nosso grupo Linguagem, Formação e Trabalho (LIFT) ${ }^{3}$. Na sequência, apontamos nosso posicionamento acerca da relação entre pesquisa e intervenção na Clínica da Atividade, a partir das ideias de Silva (2016).

No intuito de ilustrarmos de forma concreta nossa prática com a pesquisa e a intervenção na formação inicial de professores de francês da UECE, descrevemos duas pesquisas por nós realizadas - Moraes (2013) e Magalhães (2014) - esta última constituindo nossa seção de análises.

Estamos conscientes de que estas duas experiências (e outras já realizadas, que, por questões de espaço não poderemos detalhar) nos trouxeram importantes resultados e abriram perspectivas extremamente válidas para o trabalho com a formação de professores na instituição mencionada. Essas informações constituem a última seção deste artigo, que será seguida de nossas considerações finais.

\section{Clínica da Atividade: recuperando a experiência vivida}

A Clínica da Atividade, abordagem inserida no campo da teoria vigotskiana sóciohistórico-cultural do desenvolvimento humano e fortemente fundamentada na filosofia da linguagem de Bakhtin e do Círculo ${ }^{4}$, foca seus estudos na experiência vivida do trabalhador: sua atividade profissional e seu modo de agir em situação concreta de trabalho.

No entanto, a Clínica da Atividade apoiando-se em estudos de Vigotski - entende que apenas por meio da observação direta de um observador externo, não é possível aceder ao real $d a$ atividade $^{5}$ do trabalhador nem ao desenvolvimento de seu modo de agir. O objetivo, portanto, da abordagem clínica da atividade é

[...] propor o desenvolvimento e seus impedimentos como seu objeto, a clínica da atividade conclui que a única maneira de concretizar seus objetivos é através da criação de contextos que provoquem esse desenvolvimento de modo a poder estudá-lo posteriormente (LIMA; BATISTA, 2016, p. 118).

Nessa perspectiva, a criação de contextos 
propícios pode levar o trabalhador não somente a conhecer e a interpretar sua atividade, mas sobretudo a transformar sua futura situação laborativa e, eventualmente, transformar-se como profissional. Nas palavras de Clot (2006a, p. 107):

A clínica da atividade é isso: é como recurso para que os protagonistas da observação e da interpretação se transformem. Os operadores, os trabalhadores, transformam-se em sujeitos da interpretação e da observação e não se reduzem a objeto da interpretação e da observação dos pesquisadores.

O desenvolvimento da atividade e seus impedimentos precisam ser, portanto, interpretados e reinterpretados pelo próprio trabalhador a partir de métodos indiretos ${ }^{6}$ de construção e reconstrução da experiência vivida; nas palavras de Silva (2016, p. 154), “[...] o trabalhador do ofício em foco ocupa o lugar de protagonista".

Entretanto, é importante enfatizar que o analista externo - interventor ou pesquisador também se torna "[...] fonte de engajamento dos trabalhadores na análise [...]" (SILVA, 2016, p. 158), haja vista caber a este promover o diálogo do trabalhador com seu próprio trabalho. Ainda segundo Silva (2016, p. 157), "Em todo o percurso, a análise se dá em um diálogo no qual o clínico está ativo, tratando-se assim de uma coanálise."

O quadro teórico-metodológico da autoconfrontação $^{7}$ e o método da instrução ao sósia ${ }^{8}$ são entendidos como métodos indiretos de investigação e (co)análise que são utilizados no campo da Clínica da Atividade e que possibilitam contextos provocadores de desenvolvimento do trabalho e do trabalhador. Ernica (2016, p. 54), fundamentado na psicologia vigotskiana sobre o desenvolvimento humano, afirma que na Clínica da Atividade o conceito de desenvolvimento pode ser pensado:

[...] como o processo pelo qual o humano passa a apresentar um comportamento ativo, isto é, um comportamento que não é adaptação passiva e limitada às determinações do exterior mas que é voluntário, autoorientado, mediado pela consciência e pela possibilidade de antecipação da atividade e de seus objetivos. [...]. Portanto, o desenvolvimento diz respeito à formação do humano como sujeito de seu comportamento. [grifo do autor].

O quadro teórico-metodológico da autoconfrontação e o método de instrução ao sósia, tratam-se de dois processos dialógicos nos quais o(s) trabalhador(es) e o analista externo, na interação sobre a atividade do(s) primeiro(s), criam as condições necessárias para que o(s) próprio(s) trabalhador(es) desenvolva(m) por si mesmo(s) sua atividade profissional (LIMA; BATISTA, 2016). Ainda de acordo com Lima e Batista (2016, p. 123), "Tal experiência poderia lhe permitir [ao trabalhador] pensar sobre possibilidades de mudanças em um contexto no qual não houvesse apenas um expert analisando sua atividade." [grifo das autoras].

$\mathrm{Na}$ interlocução consigo mesmo, com sua atividade (passada e futura) e com o analista externo - no caso da instrução ao sósia e da autoconfrontação - e ainda, com sua atividade filmada, com seus pares e com seu coletivo profissional - no caso apenas da autoconfrontação - o trabalhador (re)formula suas próprias questões e (re)mobiliza seus conhecimentos sobre o métier para poder compreender e transformar sua situação concreta de trabalho (MAGALHÃES, 2014).

Todas essas trocas dialógicas, entendidas como "lugar e espaço do desenvolvimento" (CLOT; FAÏTA, 2016, p. 43) da atividade, assumem uma posição fundamental dentro dos estudos clínicos da atividade. São essas trocas que abrem caminho para o conhecimento sobre o métier e para que o trabalhador transforme sua atividade profissional no momento em que reconstrói sua experiência vivida. A esse propósito, Clot e Faïta (2016, p. 53-54) acrescentam que para a Clínica da Atividade:

[...] a pesquisa repousa sobre o desenvolvimento da atividade e não apenas sobre seu funcionamento. Desse ponto de vista, é preciso não apenas compreender para transformar, mas também transformar para compreender. Compreender e explicar os mecanismos do desenvolvimento passa então por uma justa apreciação da potência dos diálogos nesse desenvolvimento.

Na nossa prática, eles são mesmo a mola do desenvolvimento da atividade, de sua história. Nosso objeto é, aliás, menos a atividade como tal do que o desenvolvimento dessa atividade e de seus impedimentos. A experiência profissional não deve apenas ser reconhecida, mas transformada. Melhor, ela só pode ser reconhecida graças à sua transformação. Só a vemos quando ela muda de estatuto: quando ela se torna um meio para viver outras experiências.

Nesse sentido, compreender para 
transformar não é mais suficiente, é preciso também transformar para compreender. Ou seja, apenas compreender o funcionamento da atividade para poder transformá-la parece não mais dar conta da complexidade de uma análise clínica e/ou científica que vise aumentar o poder de agir dos trabalhadores em seu meio profissional.

As trocas dialógicas estabelecidas entre analista externo, trabalhador(es) e a atividade deste(s) último(s) podem provocar o desenvolvimento da atividade laborativa ou até mesmo do(s) próprio(s) trabalhador(es). E é exatamente esse desenvolvimento e seus impedimentos ocorridos no momento dessas trocas que passam a ser o objeto de interesse do analista que se fundamenta nas premissas da Clínica da Atividade.

O analista, portanto, estuda a atividade profissional em movimento - seus avanços, retrocessos, convergências, divergências, etc. - e dentro de um particular espaço dialógico. À luz da psicologia vigotskiana, Brandão (2016, p. 135) ratifica nosso pensamento ao afirmar que:

É somente em movimento que uma atividade pode se revelar. Até porque não conseguimos acessar o seu desenvolvimento [da atividade] diretamente, senão através de suas idas e vindas, das manifestações de seus conflitos, revelando seu caráter dialético, histórico e relativo a um gênero profissional.

Ao se tornar(em) protagonista(s) de todas essas trocas dialógicas, o(s) trabalhador(es) busca(m) perceber em sua experiência vivida, enquanto ser(es) sócio-histórico(s) e cultural(ais) que é(são), possibilidades para realizar novas experiências. Para Clot e Faïta (2016, p. 54), a abordagem clínica da atividade busca levar o trabalhador a:

[...] se desprender de sua experiência, a fim de que esta se torne um meio de realizar outras experiências. É um procedimento que pode tornar a experiência já realizada disponível para experiências a se realizar.

Daí a importância, na Clínica da Atividade, de colocar a atividade profissional em movimento, ou seja, utilizar procedimentos metodológicos indiretos que viabilizem ao(s) trabalhador(es) recuperar(em) sua experiência vivida por meio de trocas dialógicas; trocas estas que o(s) levam a se dar conta dos inúmeros conflitos profissionais e, igualmente, dos “[...] caminhos tomados e não tomados para realizar o que tem que ser realizado, apesar dos obstáculos" (BRANDÃO, 2016, p. 137).

Por tudo isso que aqui apresentamos, entendemos, assim como Silva (2016, p.156), que a Clínica da Atividade, "[...] seja na pesquisa, seja no ato clínico", compreende uma intervenção. O analista externo, seja ele pesquisador ou não, assume a responsabilidade de mediar as trocas dialógicas estabelecidas durante $\mathrm{o}$ processo interventivo, o que o faz produzir discurso, não sendo, portanto, possível considerá-lo neutro. Em outras palavras, ao usar seu saber para provocar o pensamento do(s) trabalhador(es) e pôr em andamento uma ação transformadora desse(s) mesmo(s) trabalhador(es) sobre sua própria situação de trabalho, o analista também contribui para a transformação do(s) profissional(ais) e de seu meio de trabalho (SILVA, 2016). Expomos, abaixo, uma citação de Silva (2016, p. 168) que expõe seu posicionamento sobre a questão:

A clínica da atividade pode ser feita tendo como objetivo a intervenção, sem nenhum objetivo de pesquisa no sentido acadêmico do termo. Nas situações de intervenção espera-se do clínico que auxilie os trabalhadores em seu trabalho de manutenção permanente do ofício, trabalho esse que ocorre também fora de enquadres clínicos de intervenção.

Concluímos, assim, que o desenvolvimento da atividade (e seus impedimentos) provocado pelo analista por meio de métodos indiretos de investigação e análise é a base de novos conhecimentos, tanto para que o(s) trabalhador(es) consiga $(\mathrm{m})$ ressignificar sua atividade quanto para que ele(s) se desenvolva(m) como profissional(ais).

A seção seguinte trata do construto teórico-metodológico que fundamenta as pesquisas desenvolvidas no grupo LIFT, particularmente a de Moraes (2013) e a de Magalhães (2014), que ilustram este artigo como exemplos de pesquisas cujas análises se situam nas abordagens clínica e ergonômica da atividade docente, amalgamando pesquisa e intervenção na formação inicial de professores de francês língua estrangeira (FLE).

\section{Construto teórico-metodológico das pesquisas}

O Grupo de Estudos LIFT, do qual participamos, já realizou e vem realizando pesquisas com professores estagiários de línguas estrangeiras e materna. No intuito de podermos intervir na formação desses futuros professores por meio dessas investigações que adotam as abordagens clínica e ergonômica da atividade, já 
contabilizamos cinco pesquisas realizadas e quatro que se encontram em curso.

Conforme explicitamos anteriormente, uma abordagem clínica requer admitir que aquilo que é possível acessar da atividade pela observação direta nada mais é do que uma pequena parte dessa atividade, e que somente os métodos indiretos podem viabilizar o acesso à dimensão não observável da atividade. Para isso, Vigotski (2007) fornece fundamentos "para a elaboração de métodos suscetíveis de sustentar a clínica da atividade no seu intuito de transformar contextos laborais" (LIMA; BATISTA, 2016, p.118). Ainda de acordo com as autoras, Vigotski

[...] insistiu na criação de métodos indiretos que pudessem organizar a passagem da experiência vivida em contextos diferentes com a finalidade de provocar uma duplicação dessa experiência. A criação desses espaços, definidos como espaços dialógicos, pode favorecer esse objetivo [...] (LIMA; BATISTA, 2016, p. 118). [grifos nossos].

Assim, reconhecendo a importância desses métodos para o empreendimento da análise da atividade docente, adotamos nessas investigações o quadro teórico-metodológico da autoconfrontação, processo dialógico que permite ao profissional (neste caso, especificamente, o professor em formação), a partir do filme de sua própria atividade, resignificar, em novo contexto, a experiência vivida, conforme evocado acima pelas autoras.

A decisão de utilizarmos o quadro teóricometodológico da autoconfrontação deu-se pela vantagem de se dispor das imagens - em vídeo da atividade dos professores protagonistas, pois é justamente a imagem que favorece a construção do espaço-tempo para que se possa realizar a reflexão sobre o vivido (VIEIRA; FAÏTA, 2003).

A autoconfrontação instaura entre os participantes um processo dialógico e históricodesenvolvimentista possível e, segundo os autores (VIEIRA; FAÏTA, 2003) se constitui das seguintes fases:

1) A fase da constituição do grupo de análise trata-se da composição de um grupo representativo daquele meio profissional e que, juntamente com o analista, discutirá aspectos relacionados à pesquisa ou à intervenção (como por exemplo, o objeto da pesquisa, as sequências que serão discutidas nas autoconfrontações).

2) A fase das autoconfrontações (simples e cruzada) consiste em uma conjugação das experiências profissionais. $\mathrm{Na}$ autoconfrontação simples, o profissional comenta as sequências filmadas de sua atividade inicial com o analista. $\mathrm{Na}$ autoconfrontação cruzada, dois profissionais comentam as sequências filmadas da atividade um do outro também na presença do analista.

3) A fase da extensão do trabalho de análise ao coletivo profissional trata-se de uma fase de "[...] percolação da experiência profissional posta em discussão sobre situações rigorosamente delimitadas" (CLOT et al. 2000, p. 5). Ainda de acordo com os autores, nesta ocasião é possível se estabelecer um ciclo "entre o que os trabalhadores fazem e o que eles dizem do que eles fazem, e, para terminar, o que eles fazem do que eles dizem" (CLOT et al. 2000, p. 5) ${ }^{9}$.

A pesquisa de Moraes (2013) compreendeu todas as fases da autoconfrontação, já o estudo de Magalhães (2014) constituiu-se somente da autoconfrontação simples. As duas, no entanto, desenvolveram análise e interpretação do discurso dos protagonistas (alunos e/ou professores participantes) numa perspectiva dialógica e sócio-histórica, sustentando-se nos fundamentos da teoria da enunciação círculobakhtiniana e da teoria vigotskiana do desenvolvimento humano.

\section{Pesquisa e intervenção dialogando na formação de professores}

Nesta seção, apresentamos uma breve discussão em torno de questões relacionadas à pesquisa e à intervenção no domínio da Clínica da Atividade. Iniciamos apontando algumas visões sobre esses dois movimentos trazidas por Clot (2008), Lima e Batista (2016) e Brandão (2016) que são analisadas e debatidas por Silva (2016). Logo em seguida, apontamos duas pesquisas realizadas em nosso grupo que, a nosso ver, correspondem a exemplos de intervenção.

$\mathrm{Na}$ Clínica da Atividade, segundo Clot (2008), a pesquisa consiste numa retomada da ação realizada, e com isso é possível estudar os mecanismos relacionados ao desenvolvimento ou ao impedimento de tal ação. Também compartilhando o pensamento do autor, Lima e Batista (2016, p. 128) indicam que a finalidade maior da intervenção na Clínica da Atividade consiste na restauração/ampliação do poder de agir do trabalhador. Nessa perspectiva interventiva, na qual "a clínica é ação e não apenas quadro" (CLOT, 2010, p. 77) o trabalhador (ou interlocutor) é convocado, por meio de uma atividade dialógica sobre o trabalho, a compreender e a "cuidar" do trabalho que realiza, ainda conforme Clot (2010).

Brandão (2016, p. 134) apresenta os 
elementos que distinguem pesquisa e intervenção, informa que cada uma possui "objetos, destinatários, e recursos distintos", por conseguinte, "objetivos, enquadramentos e exigências distintos" e alerta para o cuidado necessário em separar uma da outra. Obviamente a autora não ignora o fato de que a intervenção venha a se tornar pesquisa, mas defende o ponto de vista de que as duas não devem acontecer juntas, que a pesquisa deve vir antes ou depois da intervenção "para que esta última não seja comprometida pelo saber dos pesquisadores" (BRANDÃO, 2016, p. 139).

Entretanto, é importante ressaltar que, diferentemente do que acontece, a priori, nas pesquisas e intervenções em Clínica da Atividade e em Ergonomia da Atividade, nossa área de investigação (formação de professores no campo da LA), aqui no Brasil, na grande maioria das vezes, parte de uma demanda específica do próprio pesquisador. Considerando, portanto, essa particularidade, torna-se difícil separar os movimentos "coexistentes" - para utilizamos o termo empregado por Silva (2016) - da pesquisa e da intervenção. Silva (2016), debatendo os textos, destaca pontos irrefutáveis sobre os dois processos apresentados nos textos de Lima e Batista (2016) e de Brandão (2016), concorda com a ideia de que "intervenção e pesquisa se fertilizam mutuamente", mas diverge no que diz respeito ao fato de "que ocorram em momentos distintos" (SILVA, 2016, p. 160).

É fato que a Clínica da Atividade pode realizar intervenção sem objetivar a pesquisa, podendo esta vir a ser uma ação consequente, posterior àquela. Mas, reafirmamos, no contexto de sala de aula, em específico, dificilmente realizaremos uma pesquisa sem intervenção, uma vez que a presença (não-neutra) do pesquisador em sala de aula, geralmente, já interfere na ação do sujeito observado, quando provoca neste a realização de um diálogo interior. Assim, mais uma vez amparadas nos fundamentos de Silva (2016), também nos situamos a favor dessa "interferência mútua” de pesquisa e intervenção.

A nosso ver, na Clínica da Atividade sempre há uma intervenção no meio socioprofissional em que a análise se realiza. Seja efetuando uma análise no âmbito clínico ou uma análise no âmbito acadêmico, o analista externo faz uma intervenção, ele suscita uma ação transformadora no(s) trabalhadore(s) e em sua atividade profissional. Nesse sentido, vemos o pesquisador (no sentido acadêmico do termo) também como um interventor, pois ele modifica o meio no qual atua e coanalisa juntamente com o(s) trabalhador(es) o desenvolvimento da atividade profissional deste(s).

A experiência de realizar pesquisa em um locus de formação inicial reforça nosso posicionamento, tendo em vista que tem trazido certa "oxigenação" para o trabalho do formador e perspectivas de uma formação renovada e reflexiva para o professor em formação.

A seguir, focalizaremos duas pesquisas alinhadas ao grupo LIFT que se sustentam nas abordagens clínica e ergonômica da atividade. A escolha dessas duas pesquisas justifica-se pelo caráter interventivo que ambas apresentam na sua realização, em outras palavras, são pesquisas que se constituem como intervenções diretamente ligadas à formação de professores de línguas, nestes casos especificamente, a língua francesa.

A primeira pesquisa, intitulada Análise da atividade de professores de francês e elaboração de uma estratégia e de uma engenharia de formação profissional contínua: uma experiência na Universidade Estadual do Ceará (MORAES, 2013) corresponde a um projeto desenvolvido no período de 2011 a 2013, sob a coordenação de Moraes, mas em colaboração com equipes francesa e brasileira no desenvolvimento de um projeto maior subvencionado pela Agência Universitária de Francofonia ${ }^{10}$.

A proposta era desenvolver um plano de ação e transferência de aquisições e ferramentas, a partir do trabalho desenvolvido pela equipe ERGAPE, na formação de professores de francês no Brasil. Além disso, nossos propósitos específicos eram: 1) analisar a atividade docente de professores de francês em formação, realizando seus estágios curriculares no Núcleo de Línguas em turmas de mesmo nível; 2) verificar a intervenção do professor formador e o papel do coletivo de trabalho na formação e na prática docente desses estagiários, ou seja, a relação dessa prática com a própria formação; 3) analisar a relação dos estagiários com as prescrições; e 4) elaborar estratégias para a formação continuada de professores.

A pesquisa revelou dificuldades encontradas pelas alunas-estagiárias ${ }^{11}$ no que concerne ao déficit de prescrições, por consequência, a necessidade de se servir de materiais complementares; ao uso equilibrado (ou não) da língua materna na classe: quanto de português se pode usar em sala; à inviabilidade de alguns materiais ou da própria estrutura física para melhor aproveitamento do método adotado (vídeos, por exemplo); e outras. Mas também revelou a autonomia das estagiárias em assumirem a sala de aula, reconhecendo-se como "verdadeiras professoras", adaptando algumas prescrições, uma vez que, apesar de estarem 
apenas em estágio, realizam tudo o que faz um professor diplomado em atividade; e ainda, apontou marcas de transformação e ampliação do poder de agir dessas estagiárias, e aprendizagem do métier pelo próprio fazer, ou seja, nem sempre dependendo das intervenções dos formadores.

$\mathrm{O}$ estudo adotou os procedimentos de autoconfrontações simples e cruzada com as duas estagiárias. Também foi realizado um retorno ao coletivo constituído dessas mesmas protagonistas, de uma professora formadora e da coordenadora pedagógica do Núcleo de Línguas. A ocasião favoreceu o debate de questões de ordem didática (tradução na aula, uso do livro, etc.), no entanto, foram as questões de natureza ergonômica (por exemplo, o cansaço do professor), até então pouco discutidas naquele coletivo, que mais despertaram a atenção das participantes, sobretudo das formadoras. Essa experiência nos deu a confirmação de que "o que pode ser visto inicialmente, como um problema, torna-se, na verdade um trunfo, o princípio norteador em que se sustenta a metodologia históricodesenvolvimentista proposta por essa abordagem" (LIMA; BATISTA, 2016, p. 117).

A última etapa da pesquisa deu-se com uma formação piloto para professores (formadores, professores em formação, professores experientes e iniciantes) incluindo as participantes da pesquisa acima citadas. Nesta fase, a apresentação das abordagens clínica e ergonômica da atividade, com seus princípios e métodos, atraiu o interesse desses professores, despertando-lhes a conscientização de refletir e analisar o próprio trabalho, e de se dar conta de que muitos dos problemas que o professor enfrenta acontecem nos sistemas público e privado de educação, na educação básica, no ensino médio ou superior, no Brasil e em outros lugares do mundo, como, por exemplo, em escolas francesas $^{12}$.

A segunda pesquisa - retomada adiante na seção de análises - foi realizada por Magalhães (2014) e empreendeu uma intervenção numa turma de Estágio III de língua francesa. Intitulada Autoconfrontação Simples (ACS): um instrumento a serviço da formação de futuros professores de francês como língua estrangeira (FLE), esta pesquisa além de analisar o papel da autoconfrontação simples como um instrumento na formação de professores de francês, também teve como objetivos específicos identificar as dúvidas e/ou dificuldades dos formandos de francês na prática de seus estágios; demonstrar como uma reflexão suscitada a partir do trabalho de professores experientes e suas próprias reflexões sobre sua atividade poderiam ajudar esses estagiários na elucidação de suas dúvidas e/ou dificuldades e na transformação de sua (futura) prática; e, ainda, refletir sobre como a utilização da autoconfrontação, a partir da atividade de professores experientes registrada em vídeo, poderia contribuir na formação inicial desses futuros professores de francês.

Selecionamos a pesquisa de Magalhães (2014), para ilustrar nossas análises no presente estudo, a fim de sustentar nossa ideia sobre a possibilidade do uso de instrumentos e procedimentos metodológicos utilizados pela abordagem Clínica da Atividade de forma interventiva na formação inicial de futuros professores de línguas.

\section{Uma análise dialógica e clínica}

$\mathrm{Na}$ primeira parte desta seção descrevemos sucintamente o quadro geral da pesquisa de Magalhães (2014): os sujeitos, os locais de pesquisa, a escolha da disciplina de Estágio Supervisionado III, o procedimento e os instrumentos adotados para a produção dos dados e, por fim, realizamos um breve comentário sobre o papel do pesquisador na referida pesquisa, de acordo com a autora.

Já na segunda parte trazemos algumas análises de trechos extraídos dos comentários entre alunos-estagiários, professora formadora e pesquisadora durante a visualização dos vídeos das duas professoras experientes em autoconfrontação simples ${ }^{13}$.

\section{Contexto da pesquisa}

O trabalho de Magalhães (2014) que aqui trazemos como exemplo de uma pesquisa que une intervenção, pesquisa e formação inicial de professores de FLE foi realizada com um grupo de alunos do curso de Letras/Francês da UECE.

Esses alunos estavam, no primeiro semestre letivo de 2013, regularmente matriculados na disciplina de Estágio Supervisionado III $^{14}$ e participaram, juntamente com a sua professora formadora, da pesquisa em questão. Além desse grupo, havia ainda um segundo grupo de sujeitos: duas professoras experientes de FLE pertencentes ao quadro de docentes do Ensino Básico, Técnico e Tecnológico de uma outra universidade pública do mesmo Estado ${ }^{15}$.

Em relação à escolha de uma disciplina de observação para a realização da pesquisa, segundo a autora, a decisão pela disciplina de Estágio 
Supervisionado III deve-se à uma inquietação sua em relação às disciplinas de observação ${ }^{16}$ do curso de Letras/Francês da universidade onde realizou sua pesquisa e onde treze anos antes havia concluído sua licenciatura em Letras/Francês e, ainda, ao fato de os alunos-estagiários nela matriculados já terem vivenciado uma experiência em sala de aula como professores de francês durante a disciplina de Estágio Supervisionado II. Fundamentada em Gimenez (2005), Magalhães (2014, p. 35) coloca que:

Os estágios de observação oferecem aos alunos que estão em fase de formação inicial e que ainda não exercem o métier a oportunidade de um contato direto com o seu futuro campo de trabalho. No entanto, incomoda-nos continuar a ver as disciplinas que são voltadas para a observação como disciplinas que prescrevem atividades com roteiros a serem seguidos à risca, e saber que os futuros professores estão indo à sala de aula para olhá-la apenas sob um olhar contemplador, investigativo e/ou frequentemente avaliativo.

Para a autora da pesquisa em questão, a disciplina de Estágio Supervisionado III não dispunha de um "instrumento" suficientemente satisfatório para "validar" o Estágio. As fichas de observação $^{17}$ disponibilizadas pelos professores formadores da disciplina focavam, dentre outras atividades: o espaço físico, as atividades desenvolvidas, o professor, os alunos, as opções/decisões, as interações, os objetivos, as tarefas, as perguntas/respostas, os erros/correções, as situações positivas/negativas, os equipamentos técnicos, etc., porém, não davam, e nem poderiam dar conta do real da atividade do professor observado. Assim, por mais detalhadas que fossem as orientações presentes nessas fichas pedagógicas, elas nunca conseguiriam mostrar 0 real do trabalho docente:

[...] o que percebemos é que fica faltando-lhes [aos alunos-estagiários] o contato com o real do trabalho do professor observado. Em outros termos, os alunos conseguem enxergar apenas o realizado da atividade docente, mas não têm acesso à organização do trabalho do profissional nem à sua reflexão ao término da aula, isto é, as escolhas feitas, o que o professor estava pensando no momento da sua ação, aquilo que deu certo ou não, o que foi adequado e eficaz - ou não - naquele espaço de tempo. O alunos-estagiários não estão, pois, agregando à sua formação essa parte invisível e fundamental do trabalho do professor (MAGALHÃES, 2014, p. 36-37). [grifo da autora].

Além disso, a autora também considera fundamental a criação de um espaço dialógico dentro do qual alunos-estagiários, professora formadora e professores observados possam estabelecer uma relação de diálogo:

[...] tento, com esta pesquisa, eliminar - pelo menos em parte - essa neutralização comunicacional entre alunos em estágio de observação e professores experientes observados. Dizendo com outras palavras, procuro fazer com que a experiência fale à formação e busco compor um espaço interacional muito particular - ainda durante a graduação - para que os alunos possam não apenas contemplar o trabalho docente, mas também responder às suas convocações (MAGALHÃES, 2014, p. 97-98).

Isto posto, apresentamos abaixo o quadro de Magalhães (2014) que ilustra sinteticamente o procedimento e os cinco instrumentos utilizados para a construção do objeto de estudo da pesquisa em questão.

\section{QUADRO 1 - Descrição do procedimento e dos instrumentos utilizados para a construção do objeto de estudo}

\begin{tabular}{|c|c|c|}
\hline Instrumentos e procedimento & Natureza & Finalidade (s) \\
\hline \begin{tabular}{lcr} 
Instrumento & $1:$ & \multicolumn{2}{c}{ Questionário } \\
orientado & [dentro & das questões \\
levantadas & pela & abordagem \\
ergonômica da atividade docente em & \\
relação ao ensino como trabalho]
\end{tabular} & $\begin{array}{l}\text { Identificação de temas, dúvidas e/ou } \\
\text { dificuldades dos alunos-estagiários a } \\
\text { respeito do ensino como trabalho. }\end{array}$ & $\begin{array}{l}\text { Verificar temas, dúvidas e/ou } \\
\text { dificuldades dos alunos matriculados } \\
\text { na disciplina de Estágio } \\
\text { Supervisionado III de Letras/Francês } \\
\text { em relação ao ensino como trabalho; } \\
\text { Ajudar a pesquisadora na seleção das } \\
\text { sequências das atividades das } \\
\text { professoras experientes a serem } \\
\text { trazidas para uma posterior análise } \\
\text { com os alunos-estagiários e a } \\
\text { professora-formadora da disciplina de }\end{array}$ \\
\hline
\end{tabular}


Abordagem clínica na análise da atividade docente: uma via unindo pesquisa, intervenção e formação

\begin{tabular}{|c|c|c|}
\hline & & Estágio Supervisionado III. \\
\hline $\begin{array}{l}\text { Procedimento de observação para } \\
\text { familiarização }\end{array}$ & Observação para familiarização. & $\begin{array}{l}\text { Familiarizar-se com o ambiente onde } \\
\text { as duas professoras experientes } \\
\text { exercem seu trabalho e ter contato } \\
\text { inicial com as mesmas e com seus } \\
\text { alunos. }\end{array}$ \\
\hline $\begin{array}{l}\text { Instrumento 2: Filmagem das aulas } \\
\text { das professoras experientes }\end{array}$ & $\begin{array}{l}\text { Gravação em vídeo das aulas das } \\
\text { professoras experientes. }\end{array}$ & $\begin{array}{l}\text { Selecionar, editar e levar para cada } \\
\text { professora sequências de suas aulas, } \\
\text { tornando-as observadoras e } \\
\text { produtoras de um discurso sobre sua } \\
\text { própria atividade. }\end{array}$ \\
\hline $\begin{array}{l}\text { Instrumento 3: Filmagem das ACS } \\
\text { [autoconfrontações simples] com as } \\
\text { professoras experientes }\end{array}$ & \begin{tabular}{l}
\multicolumn{4}{l}{ Autoconfrontação simples: professora } \\
experiente/imagens de \\
atividade/pesquisadora.
\end{tabular} & $\begin{array}{l}\text { Abrir espaço para que as professoras } \\
\text { experientes produzam um discurso } \\
\text { sobre sua experiência vivida, } \\
\text { buscando gerar diálogos que possam } \\
\text { alimentar algumas reflexões sobre seu } \\
\text { agir profissional (atividade sobre a } \\
\text { atividade). }\end{array}$ \\
\hline $\begin{array}{lrrr}\text { Instrumento } 4: & \text { Filmagem } & \text { da } \\
\text { confrontação dos } & \text { alunos-estagiários } \\
\text { com os vídeos } & \text { das } & \text { professoras } \\
\text { experientes } & \text { em } & \text { ACS } \\
\text { [autoconfrontação simples] } & \end{array}$ & $\begin{array}{l}\text { Relação dialógica particular: } \\
\text { interação dos alunos-estagiários e } \\
\text { professora-formadora com a } \\
\text { pesquisadora, a partir das imagens das } \\
\text { professoras experientes em ACS } \\
\text { [autoconfrontação simples]. }\end{array}$ & $\begin{array}{l}\text { Instaurar uma particular relação } \\
\text { dialógica entre professores em } \\
\text { formação, professora-formadora e } \\
\text { professoras experientes, buscando } \\
\text { estabelecer uma zona potencial de } \\
\text { aprendizagem e desenvolvimento para } \\
\text { aqueles. }\end{array}$ \\
\hline $\begin{array}{lll}\text { Instrumento } & 5: & \text { Narrativa } \\
\text { autobiográfica } & & \end{array}$ & $\begin{array}{l}\text { Relato escrito dos alunos-estagiários } \\
\text { acerca de sua experiência com a ACS } \\
\text { [autoconfrontaçãor simples] } \\
\text { vivenciada durante a disciplina de } \\
\text { Estágio Supervisionado III. }\end{array}$ & $\begin{array}{l}\text { Narrar a experiência com os vídeos } \\
\text { das professoras experientes em ACS } \\
\text { [autoconfrontação simples] durante a } \\
\text { disciplina de Estágio Supervisionado } \\
\text { III. }\end{array}$ \\
\hline
\end{tabular}

FONTE: Magalhães (2014, p. 108-109). [grifos da autora].

Magalhães (2014) toma como corpus de análise o questionário orientado, o texto resultante da relação dialógica instaurada entre alunosestagiários, professora formadora, pesquisadora e imagens das professoras experientes em autoconfrontação simples e, por fim, a narrativa autobiográfica escrita pelos alunos-estagiários narrando sua experiência com os vídeos das duas professoras experientes em autoconfrontação simples.

Vale, ainda, ressaltar que Magalhães (2014), durante a análise que realizava de seu corpus fundamentando-se em Faïta e Maggi (2007, p. 62), reconhece-se como mediadora entre "o passado e o atual" dos sujeitos de sua pesquisa e, portanto, discute, em uma seção dedicada ao papel do pesquisador ${ }^{18}$, sobre a importância do pesquisador que atua no campo de uma abordagem clínica da atividade. Nas palavras da autora, o papel do pesquisador "[...] não é apenas o de coletar dados, [...], mas o de ser um mediador e um co-analista das situações dialógicas criadas no decorrer do processo" (MAGALHÃES, 2014, p. 158).
$\mathrm{Na}$ sequência, apresentamos alguns trechos extraídos do corpus da pesquisa e algumas análises realizadas por Magalhães (2014) sobre esses trechos.

\section{Um particular envolvimento dialógico}

Magalhães (2014) mostra aos alunosestagiários e à professora formadora o vídeo da atividade inicial da professora experiente $\mathrm{P} 2$ e o comentário desta sobre sua atividade. $\mathrm{O}$ assunto em discussão versava sobre $A$ segurança do professor em sala de aula ${ }^{19}$.

No vídeo de sua atividade inicial, P2 realiza uma pronúncia inapropriada na estrutura da língua francesa, mas logo em seguida se corrige. Durante a autoconfrontação simples, P2 reflete sobre situações de $\operatorname{erros}^{20} \mathrm{e}$ de aprendizados pelos quais já passou e ainda está passando como professora de francês. P2 admite que quando percebe que "erra" tenta se corrigir tão logo possível. Vejamos a fala do alunoestagiário A3 sobre a visualização do vídeo de P2 em autoconfrontação simples: 
290 A3: [...] é uma professora experiente e tá mostrando a humildade de dizer que ela não sabe tudo, que se ela tiver algum problema, que [se] ela ensinou algum conteúdo errado numa aula, na outra ela vai corrigir. Isso é ótimo pra gente que tá começando e também não tem que se culpar pelos erros que a gente tem. Então, tem que tentar melhorar, assim como ela faz, né? [grifo da autora].

[...]

292 A3: É um ótimo exemplo pra gente (MAGALHÃES, 2014, p. 136).

A fala de P2, de certa forma, conforta ou alivia "a culpa" que muitas vezes o alunoestagiário sente por cometer alguns "erros" durante a sua prática ou por ainda não saber suficientemente do métier e/ou da língua estrangeira que (vai) ensina(r). Esse processo dialógico entre alunos-estagiários, professora formadora e pesquisadora aqui estabelecido a partir da fala da professora experiente desencadeia, pois, em A3 um aprendizado, uma tomada de consciência sobre o seu papel de professor (ainda) em formação, apontando, no entanto, para uma transformação no futuro: "Então tem que tentar melhorar como ela faz, né?” (290 A3).

Em sua análise sobre a fala de A3, Magalhães (2014, p. 136-137) postula que o discurso de P2 impulsiona o processo de desenvolvimento de A3:

Cabe, pois, afirmar que o papel da professora experiente P2 em ACS [autoconfrontação simples] foi condição sine qua non para "o despertar" dos processos internos de desenvolvimento de A3: " $E$ um ótimo exemplo pra gente" (292). Essa constatação de A3 não se deu porque ela [a alunaestagiária] observou a cena da atividade inicial de $\mathrm{P} 2$, mas porque $\mathrm{P} 2$, confrontada com a sua atividade inicial, fez comentários a respeito. Algo que nos confirma que somente a simples observação da atividade inicial de professores experientes não leva os alunos em estágio de observação a compreender e a refletir sobre o real da atividade docente [...] [grifos da autora].

Magalhães (2014), à luz da filosofia bakhtiniana da linguagem e da teoria vigotskiana sócio-histórico-cultural do desenvolvimento humano, faz uma análise mais aprofundada em sua pesquisa sobre a fala de A3 acima apresentada, mostrando a importância do outro como "[...] um elemento imprescindível na constituição dos sujeitos [...]" (MAGALHÃES, 2014, p. 70). Aqui neste trabalho, devido às limitações de espaço, não é possível apresentar todos os detalhes das análises realizadas por Magalhães (2014) sobre o trecho apresentado.

\section{Um olhar transformado sobre a observação}

Ao término da visualização dos vídeos das duas professoras experientes em autoconfrontação simples, a pesquisadora interpela os alunosestagiários e a professora formadora sobre a importância daquelas visualizações durante a disciplina de Estágio Supervisionado III:

\section{P: [...] vocês acham que esses comentários [das duas professoras experientes em ACS], eles complementariam as observações que vocês fizeram durante as disciplinas de Estágio de observação?}

358 A2: Sim. [A1 concorda com A2 movimentando positivamente a cabeça].

359 A3: Sim. Porque agora a gente tem o lado deles [A3 refere-se aos professores experientes em geral] [...]. A gente segue um cronograma [A3 refere-se às fichas pedagógicas utilizadas durante a disciplina] que muitas vezes eles [professores experientes] nem têm acesso [...].

[...]

363 A1: E até a gente teve a oportunidade de ver outros pontos que a gente não...

364 A3: Não deu atenção.

365 A1: ... não viu, não prestou atenção na hora da... da observação, né?

[...]

376 A2: [A2 continua respondendo à pergunta (357) da pesquisadora] Eu acho que surte muito efeito quando você realmente confronta os experientes conosco, no caso, nós que estamos em sala de aula. Se isso fosse aplicado, digamos, no Estágio I que é só observação e o aluno não foi pra sala de aula, tudo bem, fica importante, ilustra, mas ele não vai ter a... a...

377 A3: A experiência.

378 A2: ... a experiência, né? Eu acho interessante você aplicar no aluno que esteja realmente na sua atividade docente, porque você se identifica, né? [...]. Eu acredito que deva ser uma coisa concomitante.

379 A3: Dentro da sala de aula e tendo a experiência com o vídeo pra trabalhar os dois em conjunto, antes disso eu acho também que não é muito interessante.

[...]

381 A1: [...] teve momentos que eu fiquei muito calada porque eu realmente eu ainda eu não tive uma sala de aula minha propriamente como professora, então eu realmente não ia responder uma coisa que eu não tinha certeza 
ou que eu não ia reagir daquela forma porque eu realmente não tive contato ainda em sala de aula como professora, então eu acho que precisa ter (MAGALHÃES, 2014, p. 152153).

[...]

406 A2: [...] se eu não tenho a experiência [A2 refere-se à experiência de já ter dado aula] é como eu digo, fica... acho que fica um pouco complicado você se situar, porque você não passou pela experiência né? Eu acho que ela acaba sendo essencial para que eu possa realmente me identificar com o que tá acontecendo, pra que eu possa realmente tirar dúvidas, pra que eu possa até refletir em cima da minha própria atividade num é? Às vezes a gente pensa que o trabalho da gente não é válido ou a gente acha que não tá fazendo legal, a gente às vezes se diminui também, a gente se enche de dúvidas e quando você assiste um vídeo como esse você fica é... você renova suas esperanças, suas forças né? [A3 mostra que concorda com A2 ao fazer um gesto positivo com a cabeça] você se sente até com mais ânimo pra poder entrar em sala de aula [...] (MAGALHÃES, 2014, p. 171). [grifos da autora].

Em sua análise sobre esses trechos do diálogo, Magalhães (2014) compreende que a experiência com os vídeos das duas professoras experientes em autoconfrontação simples foi enriquecedora para os alunos-estagiários da disciplina de Estágio Supervisionado III. Para a pesquisadora, essa experiência levou os alunosestagiários a refletirem sobre sua atual e/ou futura prática docente.

Observando, pois, o discurso do alunoestagiário A2 (406) [...], confirmamos o que havíamos mencionado no capítulo anterior sobre a questão do "horizonte alargado" do qual falam Vieira e Faïta (2003, p. 50), fundamentados na filosofia bakhtiniana da linguagem. Ou seja, para que os alunosestagiários se identifiquem melhor com as ACS [autoconfrontações simples] de professores experientes é preciso que aqueles consigam perceber esse "horizonte alargado" do qual fazem parte os professores experientes (MAGALHÃES, 2014, p. 173). [grifos da autora].

Ou seja, Magalhães (2014) considera positivo para a formação profissional desses futuros professores o contato com verbalizações de professores experientes sobre sua própria atividade em sala de aula durante a disciplina de Estágio Supervisonado III e que o fato de esses alunos-estagiários já terem vivenciado uma experiência prática em sala de aula como professores de francês na disciplina de Estágio Supervisionado II faz com que essas verbalizações sejam refletidas de forma mais eficaz para sua própria formação docente.

\section{A autoconfrontação simples na formação inicial: resultados e perspectivas}

Em suas análises, Magalhães (2014) entende que os alunos matriculados na disciplina de Estágio Supervisionado III se apropriaram das verbalizações das duas professoras experientes autoconfrontadas com suas atividades iniciais, transformando-as em "instrumento" 21 para auxiliar na sua atual e/ou futura prática docente.

[...] ao realizarmos nossas análises, conseguimos perceber no discurso dos alunosestagiários que as confrontações das duas professoras experientes com suas atividades iniciais os levaram a melhor compreender o real da atividade docente e o ensino como trabalho, a desenvolver um olhar mais aguçado sobre as ações pedagógicas do outro $\mathrm{e}$, consequentemente, sobre as suas próprias e a construir, desde a graduação, sentido para suas (atuais e/ou futuras) atividades em sala de aula. Ou seja, a ACS [autoconfrontação simples] demonstrou-se um instrumento (trans)formador no contexto desta pesquisa.

As observações obrigatórias, exigidas pela disciplina de Estágio Supervisionado III, foram complementadas pelos vídeos das duas professoras experientes em ACS [autoconfrontação simples] e o envolvimento dialógico ocasionado, [...] que se constituiu da observação e da reflexão de uma observação já confrontada pelo próprio profissional docente, teve um caráter (trans)formador para os alunos-estagiários envolvidos neste estudo (MAGALHÃES, 2014, p. 173). [grifo da autora].

A inserção, portanto, de aportes provenientes da abordagem clínica e ergonômica da atividade na formação de futuros professores de francês poderia ser uma forma inovadora de levar para a formação inicial o real da atividade docente. Além disso, também poderia ser salutar a interação entre alunos em estágio de observação, professores experientes observados e professor formador da disciplina de estágio de observação para o processo de construção de conhecimentos sobre o métier docente.

O quadro metodológico da autoconfrontação, 
ao dispor do vídeo da atividade inicial como principal suporte para efetuar as observações e favorecer as trocas dialógicas, proporcionou aos alunos-estagiários as condições necessárias para o desenvolvimento de diálogos reflexivos sobre a atividade docente e sobre sua própria formação inicial (MAGALHÃES; MORAES, 2016, p. 172).

Nessa perspectiva, acreditamos que os alunos em formação poderiam se beneficiar desse particular envolvimento dialógico entre formação inicial e expertise para aumentar seu poder de agir sobre suas atuais e/ou futuras práticas docentes e até mesmo sobre eles próprios.

Em suma, com o auxílio do quadro teórico-metodológico da autoconfrontação, os alunos-estagiários teriam acesso ao invisível, "porém não indizível" (MAGALHÃES, 2014, p. 37), da atividade de professores experientes em sala de aula e poderiam, desde a graduação, estabelecer um diálogo com a expertise profissional, ou seja, interagir com professores experientes e com suas reflexões sobre sua própria atividade docente.

\section{Considerações finais}

Com este breve estudo, tentamos, a partir da apresentação de duas pesquisas realizadas na UECE, mostrar como as abordagens clínica e ergonômica da atividade e seus aportes teóricometododológicos podem intervir na formação inicial de professores de FLE, contribuindo para a transformação das atuais e/ou futuras práticas desses professores, para a ampliação de seu poder de agir e, por conseguinte, para a sua própria formação profissional.

Nosso propósito foi, então, expor como alunos em formação - já em sala de aula como professores, ou não - podem, com a intervenção de um professor formador e/ou de um pesquisador, servirem-se dos princípios e métodos que sustentam os estudos clínicos e ergonômicos da atividade para refletirem e, eventualmente, para transformarem suas atuais e/ou futuras práticas em sala de aula.

Promover a verbalização do trabalhador sobre sua própria atividade em movimento e, em seguida, levar essa verbalização para o meio acadêmico de formação inicial, contribuiu, nos contextos das duas pesquisas aqui expostas, para mostrar o potencial que tem a linguagem na redução da distância entre formação inicial docente e atividade real do professor e, por conseguinte, na formação de futuros professores de FLE.

Como pudemos verificar mais detalhadamente nos exemplos da pesquisa de Magalhães (2014), os implícitos do métier docente podem ir até a sala de aula da universidade, viabilizando, assim, aos alunosestagiários - no caso específico da pesquisa em questão, entendemos os alunos da disciplina de estágio de observação - a compreensão do real da atividade dos professores observados. Mais especificamente, a autora mostrou, com sua pesquisa, que é possível instaurar um dialógo entre expertise e formação inicial e, consequentemente, ressignificar esse momento da prática de ensino.

Convém, aqui, ressaltar a importância dos pressupostos da Ergonomia da Atividade na fundamentação das duas pesquisas expostas neste artigo e esclarecer que, por limitações de espaço, optamos por apresentar apenas a Clínica da Atividade em maiores detalhes. Para maior detalhamento sobre como essas pesquisas apoiaram-se na Ergonomia da Atividade com o objetivo de intervir na formação inicial, sugerimos a leitura das mesmas na íntegra.

Achamos também importante esclarecer que por uma questão de objetivo pretendido na escrita deste artigo, não foi possível abordar, com o aprofundamento necessário, os conceitos círculo-bakhtinianos que subsidiaram as análises das duas pesquisas e nem discorrer sobre a teoria vigotskiana sócio-histórico cultural do desenvolvimento humano que, assim como Bakhtin e o Círculo, trata da linguagem como motor de desenvolvimento humano.

Em suma, a nosso ver, as duas pesquisadoras - Moraes (2013) e Magalhães (2014) - ao levarem as premissas das abordagens clínica e ergonômica da atividade e o quadro teórico-metodológico da autoconfrontação para a formação inicial de professores de FLE, intervieram positivamente para uma maior aproximação dos alunos em formação com a realidade de sua (futura) profissão e buscaram mostrar que a formação inicial docente não é um sistema de regras imutáveis e/ou inquestionáveis estabelecidas pela licenciatura em Letras/Francês da UECE. Moraes (2013) e Magalhães (2014) mostraram que há, portanto, a possibilidade de se repensar, discutir e, mesmo, transformar os atuais modelos de formação de professores de FLE nesse curso.

\section{Notas}

1 Este trabalho foi apresentado em uma mesa redonda no III Colóquio Clínica da Atividade, na Universidade de São Paulo, em outubro de 2016. Agradecimentos a Fundação Cearense de 
Apoio ao Desenvolvimento Científico e Tecnológico (FUNCAP).

2 Ver Saujat 2004.

3 O grupo de estudos LIFT está vinculado ao Programa de Pós-Graduação em Linguística Aplicada da UECE e foi fundado em 2010 por Rozania Moraes.

4 O Círculo de Bakhtin corresponde a um grupo de intelectuais, com formações e interesses diversificados, que viveram na Rússia, e que se reuniram entre os anos 1919-1929, dentre os quais destacamos Mikhail Bakhtin, Valentin Voloshinov e Pavel Medvedev.

5 Parafraseando Clot (1999 [2006]), Friedrich (2012, p. 50) afirma que "O real da atividade contém tudo o que não foi feito, mas que poderia ter sido para a realização da atividade."

6 "Sobre a questão dos métodos indiretos de análise, Clot (2011) coloca que Vigotski, em seus estudos sobre psicologia, insiste que a observação direta não é suficiente para investigar os movimentos internos não realizados pelo sujeito, sendo, pois, essencial certos métodos indiretos que consistam em organizar a reduplicação da experiência vivida" (MAGALHÃES, 2014, p. 82).

7 A autoconfrontação é um processo dialógico de análise e coanálise graças ao qual o(s) profissional(is) é (são) conduzido(s) por um analista externo a falar sobre seu trabalho e sobre sua experiência profissional a partir do filme de sua própria atividade laborativa. Detalhamos esse processo na seção seguinte.

8 Segundo Clot $(2000, \mathrm{~s} / \mathrm{n})$, a instrução ao sósia trata-se de um "exercício de instrução a um sósia". Mais precisamente, o analista externo propõe ao profissional o seguinte comando: supõe que eu sou teu sósia e que me encontro em situação de dever te substituir em teu trabalho. Quais são as instruções que devo seguir a fim de que ninguém se dê conta da substituição? Convém ressaltar que já nos anos 1970 Ivar Oddone, médico e psicológo do trabalho utilizava o método da instrução ao sósia com operários. Tal método permite ao profissional descrever ao analista a imagem e representação que ele tem de sua própria atividade. $\mathrm{Ou}$ seja, trata-se de "uma confrontação do trabalhador com os seus próprios planos, possibilitando uma crítica a tais planos e sua transformação" (MUNIZ et al. 2013, p. 287).

9 No original: "[...] une percolation de l'expérience professionnelle, mise en discussion à propos de situation rigoureusement délimitées. Un cycle s'établit entre ce que les travailleurs font et ce qu'ils en disent, et, pour terminer, ce qu'ils font de ce qu'ils disent " (CLOT et al. 2000, p. 5).

10 Agence Universitaire de la Francophonie (AUF) - trata-se de uma associação internacional que reúne, no mundo inteiro, universidades, escolas, redes universitárias e centros de pesquisas científicas tendo em comum o uso da língua francesa. Para maiores detalhes consultar o site https://www.auf.org/

11 A pesquisa teve como sujeitos duas alunas de Letras/Francês e estagiárias do Núcleo de Línguas.

12 Nesse curso apresentamos a plataforma francesa Neopass@ction e algumas situações ali analisadas. Para maiores informações consultar o site http://neo.ens-lyon.fr/neo

13 É importante ressaltar que todo o discurso dos alunos-estagiários, professora formadora e pesquisadora se apoia no filme das aulas das duas professoras experientes e nos comentários que estas fazem sobre os vídeos de suas atividades em sala de aula.

14 De acordo com o projeto pedagógico da universidade onde foi realizada a pesquisa de Magalhães (2014), o aluno do Estágio Supervisionado III cumpre $68 \mathrm{~h} / \mathrm{a}$, das quais $38 \mathrm{~h} / \mathrm{a}$ são de teoria. Inclusas nas 30 horas restantes da disciplina estão as observações obrigatórias em sala de aula de francês em cursos de idioma e para fins específicos.

15 Os alunos-estagiários são identificados na pesquisa de Magalhães (2014) por A1, A2 e A3, a professora formadora da disciplina de Estágio Supervisionado III por PF, a pesquisadora por $\mathrm{P}$ $\mathrm{e}$ as duas professoras experientes no ensino de francês língua estrangeira por P1 e P2.

16 Esclarecemos que na época da realização da pesquisa, as observações pedagógicas eram efetuadas durante a disciplina de Estágio Supervisionado I e de Estágio Supervisionado III. Nas disciplinas de Estágio Supervisionado II e de Estágio Supervisionado IV os alunos realizavam o estágio de regência.

17 Essas fichas pedagógicas utilizadas durante as disciplinas de estágio de observação são adaptações de um material em língua inglesa dos anos 1990. Para maiores informações sobre o assunto conferir Magalhães (2014) capítulo 2, seção 2.1.3.

18 Conferir Magalhães (2014) capítulo 4, seção 4.4 .

19 Todos os temas (dúvidas e/ou dificuldades) discutidos pelos sujeitos da pesquisa de Magalhães (2014) foram apontados pelos próprios alunos-estagiários nas respostas que 
estes deram no questionário orientado.

20 A palavra "erro" foi utilizada pela própria professora P2 em sua fala durante a autoconfrontação simples. Magalhães (2014, p. 157-158) diz que “[...] o quadro metodológico da autoconfrontação não tem como objetivo ir em busca dos 'erros' dos professores, mas de '[...] fazer falar os sujeitos sobre seu trabalho' (DARSES; MONTMOLLIN, 2006, p. 55), torná-los coanalistas de sua própria atividade '[...] para a transformação das situações de trabalho ordinárias"” (DUBOSCQ; CLOT, 2010/2, p. 263).

$21 \mathrm{O}$ conceito de instrumento é, aqui, entendido no sentido utilizado na psicologia vigotskiana sócio-histórico-cultural do desenvolvimento humano. Segundo Friedrich (2012, p. 66), “(..) utilizando os instrumentos psicológicos, o homem controla e influencia seu comportamento psíquico" ao buscar solucionar problemas imediatos ou ao planejar suas ações futuras.

\section{Referências}

BRANDÃO, G. R. Olhares e fazeres distintos sobre a intervenção e a pesquisa. In: BANKSLEITE, L.; SMOLKA, A. L. B.; ANJOS, D. D. (Orgs.). Diálogos na perspectiva históricocultural: interlocuções com a clínica da atividade. Campinas, SP: Mercado de letras, 2016. p. 131152.

CELANI, M. A. A. Transdisciplinaridade na Linguística Aplicada no Brasil. In: SIGNORINI, I.; CAVAlCANTI, M. C. (Orgs). Linguística Aplicada e transdisciplinaridade: questões e perspectivas. Campinas (SP): Mercado de Letras, 1998. p. 115-126.

CLOT, Y. Théorie en clinique de l'activité. In : MAGGI, B. (Dir.). Interpréter l'agir : un défi théorique. Paris : Presses Universitaires de France, 2011. p. 17-39.

CLOT, Y. Trabalho e poder de agir. Tradução de Guilherme João de Freitas Teixeira e Marlene Machado Zica Vianna. Belo Horizonte: Fabrefactum, 2010.

CLOT, Y. La recherche fondamentale de terrain: une troisième voie. Education Permanente, $\mathrm{n}^{\circ}$ 177, 2008-4. p. 67-77.

CLOT, Y. A função psicológica do trabalho.
Tradução de Adail Sobral. Petrópolis (RJ): Editora Vozes, 2006.

CLOT, Y. Entrevista : Yves Clot. Cadernos de Psicologia Social do Trabalho. Vol. 9, n. 2, 2006a. p. 99-107.

CLOT, Y. A formação pela análise do trabalho: por uma terceira via. Tradução de Claudia Osario, Kátia Santorum e Suyanna Barker. Maneiras de agir, maneiras de pensar em formação. 2000. [S.I.:s.n.]. Não paginado. Disponível em: < http://www.pqv.unifesp.br/Aformacaoatravesdaan alisedotrabalhoYvesClot.pdf>.

CLOT, Y.; FAÏTA, D. Gêneros e estilos em análise do trabalho: Conceitos e métodos. Tradução de Rozania Moraes e Aline Leontina Gonçalves Farias. Revista Trabalho \& Educação. Belo Horizonte: v. $25 \mathrm{n}^{\circ}$ 2, 2016. p. 33-60. Disponível em: < http://www.portal.fae.ufmg.br/revistas/index.php/t rabedu/issue/view/102>.

CLOT, Y.; FAÏTA, D. Genres et styles en analyse $\mathrm{du}$ travail: Concepts et méthodes. Travailler: Revue Internationale de Psychopathologie et de Psychodynamique du Travail; $n^{\circ} 4,2000$. p. 7-42. Disponível em:

http://psychanalyse.cnam.fr/revue-

travailler/presentation-et-sommaire/numero4/theorie-genres-et-styles-en-analyse-du-travailconcepts-et-m-thodes--467242.kjsp >.

DARSES, F.; MONTMOLLIN, M. L'ergonomie. 4. ed. Paris : Éditions La Découverte, 2006.

DUBOSCQ, J.; CLOT, Y. L'autoconfrontation croisée comme instrument d'action au travers du dialogue : objets, adresses et gestes renouvelés. Revue d'anthropologie des connaissances. Vol 4, $\mathrm{n}^{\circ}$ 2, 2010/2. p. 255-286. Disponível em: $<$ http://www.cairn.info/revue-anthropologie-desconnaissances-2010-2-page-255.htm>.

ERNICA, M. Prescrição e desenvolvimento em situação de trabalho. In: BANKS-LEITE, L.; SMOLKA, A. L. B.; ANJOS, D. D. (Orgs.). Diálogos na perspectiva histórico-cultural: interlocuções com a clínica da atividade. Campinas, SP: Mercado de letras, 2016. p. 49-57.

FAÏTA, D.; MAGGI, B. Un débat en analyse du travail - Deux méthodes en synergie dans l'étude d'une situation d'enseignement. Toulouse, France: Octarès Editions, 2007. 
FREIRE, P. Pedagogia da autonomia: saberes necessários à prática educativa. $25^{\mathrm{a}}$. ed. São Paulo: Paz e Terra, 1996.

FRIEDRICH, J. Lev Vigotski mediação, aprendizagem e desenvolvimento: uma leitura filosófica e epistemológica. Tradução de Anna Rachel Machado e Eliane Gouvêa Lousada. Campinas (SP): Mercado de Letras, 2012.

GIMENEZ, T. Desafios contemporâneos na formação de professores de línguas: contribuições da Linguística Aplicada. In: FREIRE, M.; VIEIRA-ABRAHÃO, M. H.; BARCELOS, A. M. F. (Orgs.). Linguística e Contemporaneidade. ALAB (Associação Brasileira de Linguística Aplicada), Campinas, SP: Pontes, 2005. p. 183201.

LIMA, M. S. L. Estágio e Aprendizagem da profissão docente. Brasília: Liber Livro, 2012.

LIMA, M. E. A.; BATISTA, M. A. O papel do expert/especialista versus clínico/intervenant em clínica da atividade - afinal quem analisa a atividade de trabalho? In: BANKS-LEITE, L.; SMOLKA, A. L. B.; ANJOS, D. D. (Orgs.). Diálogos na perspectiva histórico-cultural: interlocuções com a clínica da atividade. Campinas, SP: Mercado de letras, 2016. p. 113129.

MACHADO, A. R. Apresentação. In: MACHADO, A. R. (Org.). O Ensino como trabalho: uma abordagem discursiva. Londrina: Eduel, 2004, p. vii-xx.

MAGALHÃES, E. M. Autoconfrontação Simples (ACS): um instrumento a serviço da formação profissional de futuros professores de francês como língua estrangeira (FLE). 2014. Dissertação. (Mestrado Acadêmico em Linguística Aplicada) Universidade Estadual do Ceará, Fortaleza.

MAGALHÃES, E. M.; MORAES, R. M. A. Autoconfrontação Simples (ACS): um instrumento de formação docente. In: SOUZA et al. (Orgs.). I Coletânea de teses e dissertações da UECE. Fortaleza: EdUECE, 2016. p. 154-179.

MORAES, R. M. A. Análise da atividade de professores de francês e elaboração de uma estratégia e de uma engenharia de formação profissional contínua: uma experiência na Universidade Estadual do Ceará. Projeto de Pesquisa, Fortaleza: Universidade Estadual do Ceará, 2013.

MUNIZ, H. P.; BRITO, J.; SOUZA, K. R.; ATHAYDE, M.; LACOMBLEZ, M. Ivar Oddone e sua contribuição para o campo do trabalhador no Brasil. Rev. bras. Saúde ocup., São Paulo, 38 (128): 280-291, 2013.

SILVA, C. O. Pesquisa e intervenção: movimentos que se cruzam e coexistem, em mútua interferência. In: BANKS-LEITE, L.; SMOLKA, A. L. B.; ANJOS, D. D. (Orgs.). Diálogos na perspectiva histórico-cultural: interlocuções com a clínica da atividade. Campinas, SP: Mercado de letras, 2016. p. 153168.

SAUJAT, F. Spécificités de l'activité d'enseignants débutants et "genres de l'activité professorale", Polifonia, v. 8, n. 08, 2004. Disponível em :

http://periodicoscientificos.ufmt.br/ojs/index.php/ polifonia/article/view/1128/892.

VIEIRA, M.; FAÏTA, D. Quando os outros olham outros de si mesmo: reflexões metodológicas sobre a autoconfrontação cruzada. Polifonia, $\mathrm{n}^{\circ} 7$, Cuiabá: EdUFMT, 2003. p. 27-67. Disponível em: < http://cpd1.ufmt.br/meel/arquivos/artigos/230.pdf>.

VIGOTSKY, L. S. A formação social da mente: o desenvolvimento dos processos psicológicos superiores. Tradução de José Cipolla Neto, Luis Silveira Menna Barreto e Solange Castro Afeche. 7. Ed. São Paulo: Martins Fontes, 2007. 


\section{Sobre os Autores:}

Rozania Maria Alves de Moraes é professora Adjunta do Curso de Letras e do Programa de Pós-Graduação em Linguística Aplicada da Universidade Estadual do Ceará (UECE). Possui Doutorado em Ciências da Linguagem, pela Universidade Grenoble III (2005), e Pós-Doutorado em Ciências da Educação, pela Universidade Aix-MArseille (2012).

Elisandra Maria Magalhães é doutoranda do Programa de Pós-Graduação em Linguística Aplicada da Universidade Estadual do Ceará. Bolsista da FUNCAP (Fundação Cearense de Apoio ao Desenvolvimento Científico e Tecnológico).

Recebido em julho de 2017.

Aprovado em julho de 2017. 